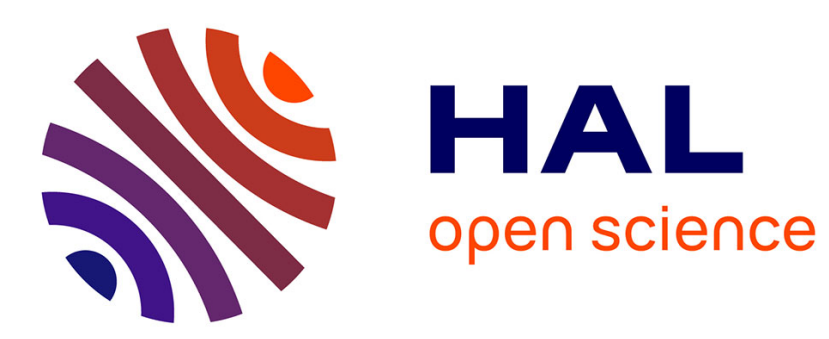

\title{
High-Temperature Brittleness and Interfacial Segregation in Tin Bronzes
}

\author{
W. Ozgowicz, M. Biscondi
}

\section{To cite this version:}

W. Ozgowicz, M. Biscondi. High-Temperature Brittleness and Interfacial Segregation in Tin Bronzes. Journal de Physique IV Proceedings, 1995, 05 (C7), pp.C7-315-C7-320. 10.1051/jp4:1995738 . jpa00254032

\section{HAL Id: jpa-00254032 https://hal.science/jpa-00254032}

Submitted on 1 Jan 1995

HAL is a multi-disciplinary open access archive for the deposit and dissemination of scientific research documents, whether they are published or not. The documents may come from teaching and research institutions in France or abroad, or from public or private research centers.
L'archive ouverte pluridisciplinaire HAL, est destinée au dépôt et à la diffusion de documents scientifiques de niveau recherche, publiés ou non, émanant des établissements d'enseignement et de recherche français ou étrangers, des laboratoires publics ou privés. 


\title{
High-Temperature Brittleness and Interfacial Segregation in Tin Bronzes
}

\author{
W. Ozgowicz and M. Biscondi* \\ Institute of Physical Metallurgy, Silesian Technical University, ul. Konarskiego 18a, 44-100 Gliwice, \\ Poland \\ * Ecole des Mines, 158 cours Fauriel, 42023 Saint-Etienne cedex 2, France
}

\begin{abstract}
This paper presents preliminary results of Auger electron spectroscopy performed on fractured specimens of copper and tin bronzes at the time of in situ hot tensile tests. They show interfacial segregation of $\mathrm{Sn}, \mathrm{P}$ and $\mathrm{S}$, according to the materials and the test temperature. In comparing these results and the mechanical behaviour of the materials, we discuss the effect of the interfacial segregations on the drop in ductility at intermediate temperatures and on its restoration by dynamic recrystallisation.
\end{abstract}

\section{INTRODUCTION}

A minimum of ductility at homologous temperatures of approximately 0.5 and accompanying intercrystalline fracture are the characteristic features observed during hot deformation of copper and its alloys, especially those with low stacking fault energies.

The causes of such low ductility are not fully understood, although they are often explained by several fracture mechanisms involving grain boundary sliding and intercrystalline cavitation, combined with the effects of precipitation and grain boundary segregation of alloying elements and impurities [1-10]. If there are still many controversies with regard to the mechanism of microcrack nucleation, the problem of propagation of the cracks is much less controversial and this process is attributed to diffusive movement of vacancies towards the crack, grain boundary sliding and crack tip stress concentration. At temperatures higher than half the melting point, ductility can be more or less restored through dynamic recrystallization : the grain boundaries escape away from microcracks and these, isolated inside the grains, can only grow very slowly.

Much less attention has been paid to the effects of intercrystalline segregation on grain boundary migration and intercrystalline cracking mechanisms. Also, fundamental experimental data for copper and its alloys are rather scarce in this respect [11-17]. In this situation, the objective of this work was to study the role of alloying elements and impurities in the promotion of potential intercrystalline segregation and its effect on the fracture of copper and tin bronzes during hot deformation. This paper presents preliminary results of Auger Electron Spectroscopy (AES) on rupture surfaces resulting from in situ hot deformation tests, in relation to the chemical composition of the materials and deformation temperature.

\section{2 - EXPERIMENTAL PROCEDURE}

\section{2-1 - Materials}

Five materials were compared : Table 1 gives the content levels of elements detected by Auger spectroscopy measurements.

The industrial bronze (supplied by Tréfimétaux in the form of an $11.6 \mathrm{~mm}$ diameter bar) was produced by semi-continuous casting. Details of preparation of the synthetic alloys and heat treatments were described in an earlier publication [10]. All the materials are in the annealed state, with a grain size close to 0.2 $\mathrm{mm}$, except that of the industrial alloy, which is double that value. 
Table 1: Content levels of significant elements (in wt. per cent)

\begin{tabular}{|c|c|c|c|c|c|}
\hline & \multicolumn{2}{|c|}{ Coppers } & \multicolumn{2}{|c|}{ Synthetic bronzes } & \multirow[b]{2}{*}{$\begin{array}{l}\text { Industrial } \\
\text { alloy }\end{array}$} \\
\hline & $\begin{array}{c}99.999 \% \\
\text { (Asarco) }\end{array}$ & $\begin{array}{l}99.99 \% \\
\text { (OFHC) }\end{array}$ & CuSn6 & CuSn6P & \\
\hline Sn & -- & $\cdots$ & 6 to 7 & 6 to 7 & 6.7 \\
\hline $\mathbf{P}$ & $\cdots$ & $\cdots$ & -- & 0.3 & 0.42 \\
\hline $\mathrm{S}$ & $3.10^{-4}$ & $9.10^{-4}$ & $5.10^{-4}$ & $4.10^{-4}$ & $10.10^{-4}$ \\
\hline
\end{tabular}

\section{2-2 - In situ hot tensile tests}

Small cylindrical samples (minimum diameter $2 \mathrm{~mm}$, useful length $12 \mathrm{~mm}$ ) were set in a specially designed micro-tensile attachment in the Auger spectrometer, then electric resistance-heated to the chosen temperature (in the range $100-600^{\circ} \mathrm{C}$ ) in about $10 \mathrm{~min}$., in a vacuum of approximately 10-7 Pa.

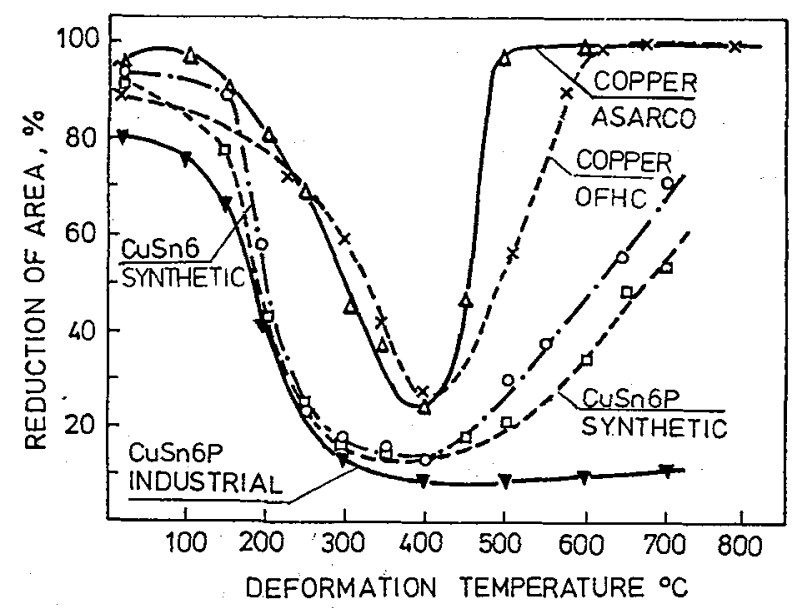

Figure 1 : Influence of deformation temperature on the reduction of area at rupture of copper and tin bronzes, tensile strained at $10^{-3} \mathrm{~s}^{-1}[10]$.

After a few minutes, samples were strained at a rate of about $10^{-4}-10^{-3} \mathrm{~s}^{-1}$ till fracture, which leads to rapid cooling. These deformation conditions are close to those employed in our previous study [10], in which a ductility loss was shown for the materials under investigation in the present study (Fig. 1).

AES analyses of selected areas on intercrystalline fracture surfaces were carried out directly after rupture, before any contamination.

\section{2-3 - Rupture surface analysis}

For each specimen, AES measurements were performed on more than ten areas. Spectrograms in the derived mode were obtained from a Riber system, comprising a cylindrical mirror analyzer and a coaxial gun. The primary electron energy was fixed at $3 \mathrm{KeV}$, so that the beam diameter was a few microns. The estimation of the chemical composition on the rupture surfaces results from a method we have proposed for quantitative AES [18], using an appropriate multicomponent standard set, that is, in the present case, the industrial alloy and the compounds $\mathrm{Cu}_{3} \mathrm{P}$ and $\mathrm{Cu}_{2} \mathrm{~S}$. Moreover we have supposed that segregation occurs only in the surface monolayer.

Because of the poor quality of the images obtained from the secondary electrons in the Auger spectrometer, it was necessary to perform fractographic examinations after the samples left the spectrometer, using a scanning electron microscope. 


\section{3 - RESULTS}

It should be noted that, for a given material and a given temperature, topographic fracture surface features are practically the same whether the tensile test takes place in situ (cf. \$2-2) or in a conventional manner in $\mathrm{Ar}$, at a strain rate of $10^{-3^{*}} \mathrm{~s}^{-1}[10]$.

\section{3-1 - Industrial alloy}

\section{3-1-1 - Fractography}

When the tensile temperature increases, the rupture becomes fully intergranular from $250^{\circ} \mathrm{C}$. Between this temperature and $350^{\circ} \mathrm{C}$, two types of intergranular facets appear. Some of them (Figures 2 and 3) are formed of small dimples, apart from a few big cavities probably resulting from the manufacturing process. Most of the facets (Figures 2 and 4 ) are much smoother, with traces of deformation bands and without clear evidence of cavitation.

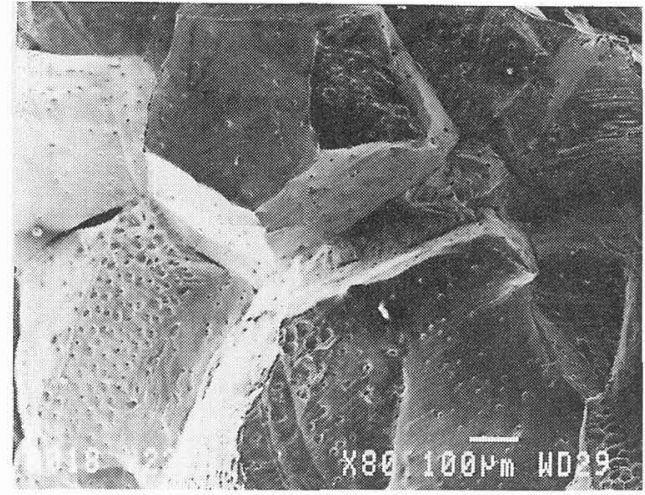

Figure 2 : Fracture surface of industrial alloy deformed at $300^{\circ} \mathrm{C}$.

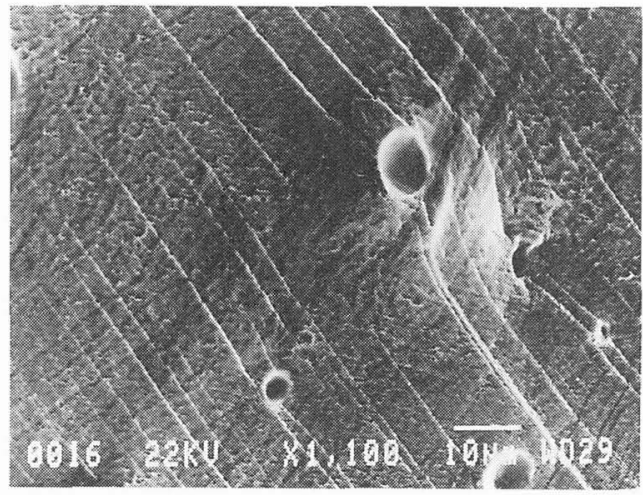

Figure 4 : Zone B in Figure 2, at higher magnification.

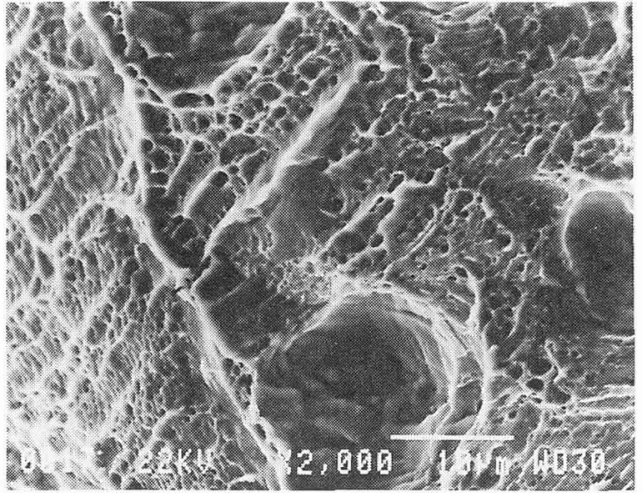

Figure 3 : Zone A in Figure 2, at higher magnification.

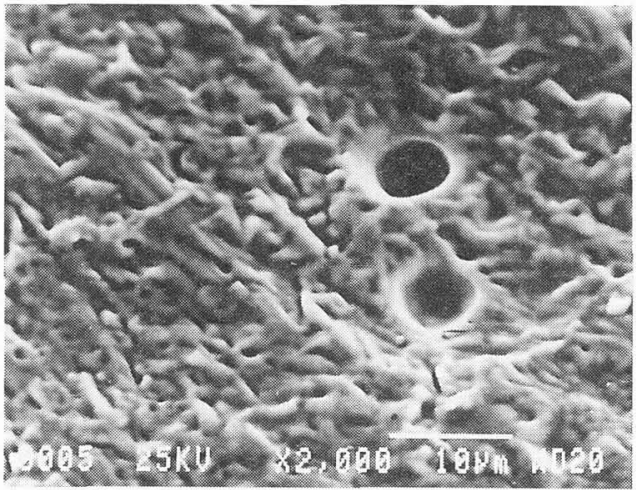

Figure 5 : Fracture surface of industrial alloy deformed at $500^{\circ} \mathrm{C}$.

From $400^{\circ} \mathrm{C}$, the fracture surfaces appear rougher, totally covered with microdimples arising from intergranular cavities produced during hot deformation and partially smoothed by surface diffusion (Figure 5). 


\section{3-1-2 - Chemical surface analysis}

The rupture surfaces are enriched in $\mathrm{Sn}, \mathrm{P}$ and $\mathrm{S}$ (Figure 6). The rapid decrease in the amounts of these elements, when the surface is ion-etched, indicates that they have segregated in a thin layer.

When the deformation temperature increases (Figure 7), the surface enrichment of $P$ increases to $400^{\circ} \mathrm{C}$ and then remains constant (about 20). The surface content of $S$ remains relatively low (a few percent) till $400^{\circ} \mathrm{C}$ and grows rapidly to 15 at.\% (corresponding to an enrichment factor of $10^{4}$ ) above this temperature. The Sn surface content increases up to $300^{\circ} \mathrm{C}$ and then decreases because of the increase in $P$ and $S$ contents ; the $S n$ enrichment factor lies between 2 and 4.

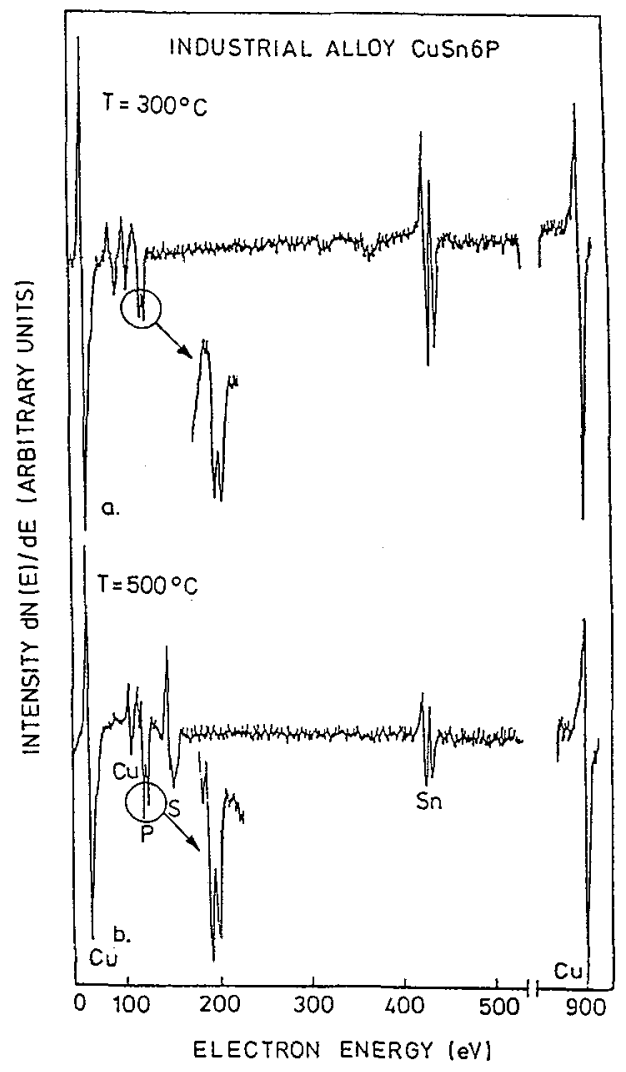

Figure 6 : AES spectra from intergranular fracture facets of industrial alloy, deformed at $300^{\circ} \mathrm{C}$ (a) and $500^{\circ} \mathrm{C}$ (b). The double peak at $117-120 \mathrm{eV}$ relative to phosphorus can be attributed to $\mathrm{Cu}-\mathrm{P}$ bonds : AES analysis of $\mathrm{Cu}_{3} \mathrm{P}$ compound shows a similar doublet.

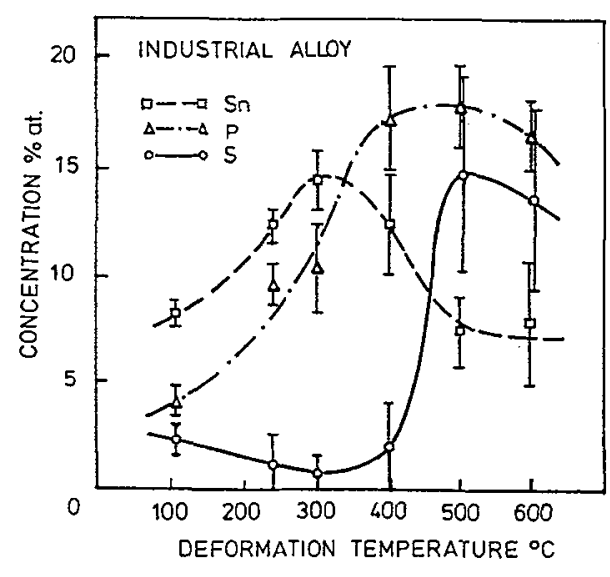

Figure $7: P, S$ and $S n$ concentrations on rupture surfaces, as functions of deformation temperature, for the industrial alloy.

\section{3-2 - Synthetic alloys and coppers}

For the synthetic alloy CuSn6P, the fractographic features are the same as those for the industrial alloy. The $\mathrm{P}$ enrichment on the rupture surfaces, as a function of the deformation temperature (Figure 8), is the same as for the industrial alloy, considering the respective bulk contents. The surface concentration of sulphur remains limited to values close to the AES detection limit, up to $500^{\circ} \mathrm{C}$, then grows to 5 at. $\%$ for higher temperatures. Such low concentrations are in keeping with the sulphur bulk content of this alloy (half of that for the industrial alloy). Tin surface concentration grows with deformation temperature up to 
17 at.\%, at $300^{\circ} \mathrm{C}$, then remains almost constant because of the constancy of $\mathrm{P}$ segregation and the relatively weak sulphur segregation, for higher temperatures.

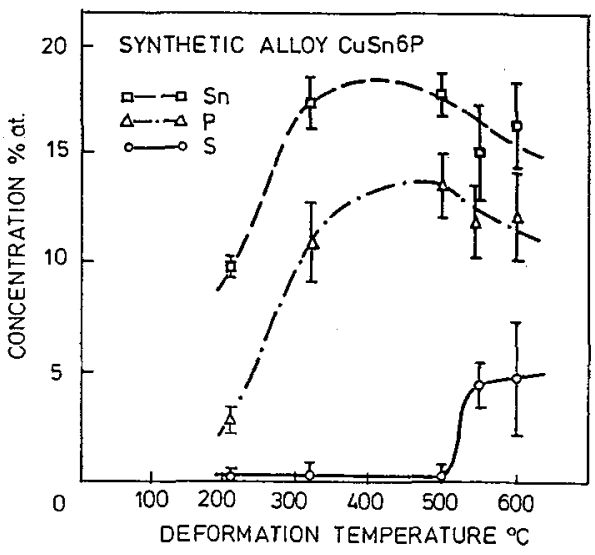

Figure $8: P, S$ and $S n$ concentrations on rupture surfaces, as functions of deformation temperature, for the synthetic alloy CuSn6P.

In the case of the synthetic alloy $\mathrm{CuSn6}$, the fractographic character of the rupture is no different from that of the industrial alloy, except at $600^{\circ} \mathrm{C}$, where the rupture becomes partially intragranular. Whatever the deformation temperature, neither $\mathrm{P}$ nor $\mathrm{S}$ was detected by AES on the rupture surfaces. The $\mathrm{Sn}$ content grows from 15 at. $\%$ to 25 at.\% as deformation temperature increases from $300^{\circ} \mathrm{C}$ up to $600^{\circ} \mathrm{C}$.

Finally, for both coppers, the ruptures are intragranular, except around $400^{\circ} \mathrm{C}$ where they have a mixed character. For this temperature, on the intergranular zones, we observed no segregation in the Asarco copper, but a low sulphur content (about 3 at.\%) in the OFHC copper.

\section{4 - DISCUSSION AND CONCLUSIONS}

First of all, let us compare the ductile to brittle transition temperature $\mathrm{T}_{\mathrm{E}}$ (for which the ductility drop is observed) and the interfacial segregations measured after fracture, for the different materials we have observed. As fractures result from grain boundary cavitation, the segregations measured have very likely occured on cavity surfaces during deformation.

Regarding copper, the role of sulphur, which is known for strongly segregating at its interfaces, has been emphasized [16]. But in our case, the sulphur interfacial contents measured were weak or very weak, so we cannot conclude that it has a discernible effect on the phenomena which explain hot brittleness, that is on grain boundary sliding rate and intergranular cavitation kinetics.

For all the tin bronzes studied, $T_{E}$ is practically the same, irrespective of the interfacial amounts of sulphur and phosphorus measured between 200 and $400^{\circ} \mathrm{C}$ : again, these segregations have only a minor role on the hot embrittlement mechanisms. On the other hand, tin has a manifest effect in lowering $\mathrm{T}_{\mathrm{E}}$ by more than $100^{\circ} \mathrm{C}$. Sn can play different roles, of which we cannot appreciate the relative importance. Its bulk content of $7 \mathrm{wt} \%$ decreases the stacking fault energy to about $30 \mathrm{~mJ} / \mathrm{m}^{2}$, which promotes localized slip and stress concentrations at grain boundaries and triple points. To this can be added the possible effects of interfacial enrichment in tin : an increase in grain boundary sliding and/or the intergranular cavity growth rate, weakening of intergranular cohesion, suggested by some microscopical observations (Figure 4).

For the improvement of ductility which can occur above $400^{\circ} \mathrm{C}$, the interfacial segregation of sulphur seems to have a harmful role in delaying dynamic recrystallization and/or in speeding up cavity growth. This appears for copper when we compare the two kinds of metals studied, and for tin bronzes if we compare the industrial alloy with the synthetic CuSn6P alloy (Figures 1,7 and 8). In this connection, the delaying role of sulphur on dynamic recrystallization has been underlined by other authors in the case of copper [16] and brass [17]. Moreover, by comparing the ductility of the OFHC copper, the CuSn6 alloy and the synthetic CuSn6P alloy (Figure 1) and by considering the interfacial segregations in these materials between 400 and $600^{\circ} \mathrm{C}$ (Figures 7 and 8), it appears that $P$ could hinder grain boundary 
migration and/or accelerate intergranular cavitation growth. The role of tin is not clear : it can act in the bulk by decreasing the stacking fault energy and so modifying the cold-working conditions, it can decrease grain boundary mobility by its segregation at grain boundaries and it can also act on cavitation growth by its segregation on cavity surfaces.

Finally, in the competition between intergranular cavitation and dynamic recrystallization, which explains the minimum of ductility of the coppers and tin bronzes studied at intermediate temperatures, interfacial segregations of $\mathrm{Sn}, \mathrm{P}$ and $\mathrm{S}$ could accelerate cavity growth and reduce grain boundary mobility. As for the ductile-brittle transition temperature $T_{E}$, it seems especially to depend on alloying effects on plastic deformation behaviour, via the stacking fault energy, and perhaps on the effect of grain boundary segregation on the intergranular sliding rate.

\section{References}

[1] Raj R., Acta Met., 26 (1978), 995.

[2] Izumi O. and Jamagata H., Jap. Met. Soc., 17 (1978), 165.

[3] Izumi O., Jap. Met. Soc., 18 (1979), 15.

[4] Evans A.G., Acta Met., 28 (1980), 1155.

[5] Wilkinson D.S., Mat. Sci. Eng., 49 (1981), 31.

[6] Nix W.D., Scripta Met., 17 (1983), 1.

[7] Bochniak W., Arch. Hutn., 30 (1985), 77.

[8] Orman L., Arch. Hutn, 30 (1985), 377.

[9] Kandra J. and Cosandey F., Scripta Met., 19 (1985), 397.

[10] Ozgowicz W. et Biscondi M., Mém. Et. Sci. Rev. Mét., 3 (1987), 129.

[11] Levin D. and Rapperport E., Scripta Met., 2 (1968), 165.

[12] Hanneman E. and Anthony R., Scripta Met., 2 (1968), 485.

[13] Watanabe W., Obata M. and Karashima S., Scripta Met., 15 (1981), 965.

[14] Grovenor M. and Rae F., Scripta Met., 15 (1981), 1305.

[15] Chuang T.H., Gust W. and Heldt A., Scripta Met., 16 (1982), 1437.

[16] Shibayanagi T., Saji S. and Hori S., "Improvement of low ductility failure in copper", Grain Boundary Structure and Related Phenomena (JIMIS-4), Minakami 25-29 November 1995, Supplement to Trans. Jap. Inst. Met., 27 (1986), p. 943.

[17] Kanno M, and Shimodaira N., Scripta Met., 21 (1987), 1487.

[18] Perrot-Simonetta M.-Th., Lorenzon C. and Biscondi M., Surf. and Interface Anal., 21 (1994), 316. 